\title{
Heterogeneous Metal-Organic Framework Catalysts for Suzuki-Miyaura Cross Coupling in the Pharma Industry
}

\author{
Daniele Cartagenova ${ }^{a}$, Stephan Bachmann ${ }^{\star b}$, Jeroen A. Van Bokhoven ${ }^{\text {ac }}$, Kurt Püntener ${ }^{\mathrm{b}}$ and \\ Marco Ranocchiari*a
}

\begin{abstract}
The synthesis of drug substances (DS) requires the continuous effort of the pharma industry to ensure high sustainability standards. The Suzuki-Miyaura cross coupling is a fundamental $\mathrm{C}-\mathrm{C}$ bond-forming reaction to produce complex DS intermediates. The present contribution points out the way in which the synthesis of DS intermediates by $\mathrm{C}-\mathrm{C}$ cross coupling can be economically competitive, while minimizing waste by selecting the appropriate heterogeneous catalyst. By comparing homogeneous, immobilized heterogeneous catalysts on silica and metal-organic framework (MOF) catalysts, while considering the perspectives of academia and industry, the critical parameters for a successful industrial application of heterogeneous catalytic Suzuki-Miyaura cross coupling reactions were identified. Heterogeneous catalysts, such as MOFs, may provide a complementary platform for reducing waste and the costs of production related to such transformations.
\end{abstract}

Keywords: Catalysis · Metal-organic framework · Pharma Industry · Sustainable organic processes · SuzukiMiyaura Cross Coupling

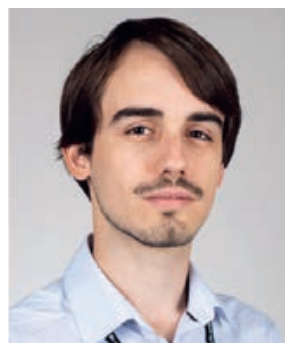

Daniele Cartagenova received his Bachelor's (2015) and Master's (2018) degrees in Chemistry from the Università degli Studi di Genova in Italy. He is currently a $\mathrm{PhD}$ candidate at the Paul Scherrer Institute and the ETH Zurich and is focusing on the development of molecularly defined heterogeneous catalysts with metalorganic frameworks.

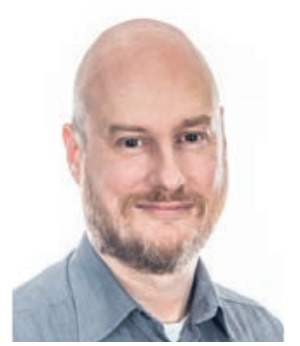

Dr. Stephan Bachmann obtained his diploma in chemistry (1998) and his PhD (2003) at the ETH Zurich. After a postdoctoral stay at Aarhus University in Denmark, Stephan joined the catalysis section of F. Hoffmann-La Roche Ltd in 2004, where he has been working ever since. The main focus of Stephan's work lies in the development and implementation of robust, catalytic processes on a technical scale, ranging from very early to late-phase (clinical) supply. His key expertise includes the development of catalytic solutions for homogeneous and heterogeneous hydrogenation, carbonylation as well as $\mathrm{C}-\mathrm{X}$ couplings. In the past few years non-noble metal catalyzed processes have also become a major topic of interest.

${ }^{*}$ Correspondence: Dr. M. Ranocchiaria , Dr. S. Bachmann ${ }^{\text {, }}$

E-mail: marco.ranocchiari@psi.ch; stephan.bachmann@roche.com

aPaul Scherrer Institute, Laboratory for Catalysis and

Sustainable Chemistry, Forschungsstrasse 111,

$\mathrm{CH}-5232$ Villigen PSI, Switzerland:

${ }^{b}$ F. Hoffmann-La Roche Ltd., Department of Process Chemistry \& Catalysis,

Grenzacherstrasse 124, CH-4070 Basel, Switzerland;

${ }^{\circ}$ ETH Zurich, Institute for Chemical and Bioengineering, $\mathrm{CH}-8093$ Zurich

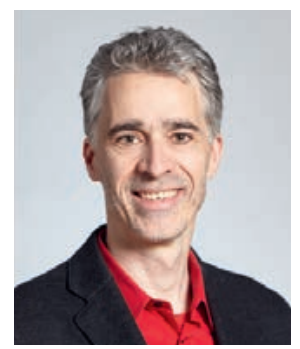

Prof. Dr. Jeroen A. van Bokhoven obtained his $\mathrm{PhD}$ from Utrecht University, The Netherlands, in 2000. Since 2006 he he has been a professor at ETH Zurich and, since 2010, head of the Laboratory for Catalysis and Sustainable Chemistry at the Paul Scherrer Institute. His interest is heterogeneous catalysis and the development of novel catalysts and processes aimed at energy and the environment. Through understanding the catalytic process with novel characterization and targeted synthesis, his aim is the design of new catalytic materials.

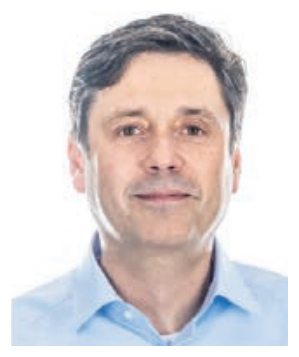

Dr. Kurt Püntener obtained his diploma in chemistry (1990) and his PhD (1994) in the group of Prof P. Pregosin (ETHZ). After postdoctoral stays at Colorado State University (USA) and Philipps University Maarburg (Germany) in the research groups of Prof L.S. Hegedus and Prof. P. Knochel, Kurt joined the catalysis group of Process Research \& Synthesis at F. Hoffmann-La Roche Ltd in 1996. After his promotion to group leader (2011), he was nominated in 2013 for the position of Head of Process Research at the Roche Innovation Center in Basel where he is responsible for preclinical process research for small molecules, peptides, and oligonucleotide drug substances. In 2019, Kurt became Head of Roche's Catalysis \& Flow Reaction section, which focuses on the design of enzymatic, microbial, and metal-catalyzed transformations as well as continuous processes for the development of robust and cost-efficient drug substances. 


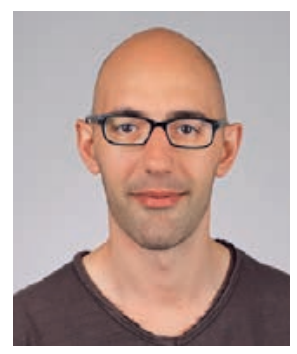

Dr. Marco Ranocchiari received his Master's degree in chemistry in 2005 from the Università degli Studi di Milano in Italy. He completed his PhD at the ETH Zurich in 2009. In 2010, he joined the Paul Scherrer Institute in the Laboratory for Catalysis and Sustainable Chemistry and has been a group leader since 2016. His research focuses on energy-related catalysis and metal-organic frameworks for catalytic applications. He is co-founder of the spin-off novoMOF AG (https://novomof.com), a custom MOF manufacturing company.

\section{Introduction}

The chemical community must be on the lookout for new, innovative technologies that potentially reduce the costs of drug substance (DS) manufacturing processes due to the increasing pressure on the pharmaceutical industry to provide affordable drugs and ultimately cost-efficient therapeutic modalities for innovative healthcare. These new technologies originated primarily from basic research conducted, for example, at academic institutions. When taken up by the pharmaceutical industry, these technologies are first tested in a feasibility study to determine their scope and limitations with regard to specific aims. To find out whether their use in a process step is expected to add an anticipated benefit, the new process undergoes a detailed phase of development before its employment in a manufacturing process. This ensures that the investment is worthwhile and the resulting process is safe and robust. A key aspect of the successful implementation of a new technology is that it results in a reduction in cost and achieves a more sustainable process. Not only individuals, but also health authorities require efficient drug manufacturing processes, which are safe, form minimal amounts of chemical waste, and make optimal use of limited natural resources. In recent years, different metrics were introduced to guide chemists in determining the 'greenness' of a process and, ultimately, its optimization. One of the most prominent metrics, the PMI (Process Mass Index $=\mathrm{kg}$ reagents and solvents $/ \mathrm{kg}$ of API), has become widely accepted in the chemistry community. Companies like Roche constantly monitor the PMI values of their drug substance processes, from the early developmental phase to the launch of supplies and to trigger final process optimization, e.g. by employing innovative technologies that might have emerged during the developmental/commercialization phases of a DS. In addition to the financial and environmental aspects, the generation of own or shared intellectual property (IP) with regard to new technologies in (established) drug substance processes also plays an important role. It secures freedom-to-operate of the processes and can result in competitive advantages.

In numerous process steps in today's synthesis of drugs, well-defined homogeneous rhodium, palladium, ruthenium, and iridium catalysts, bearing organic ligands to tune the catalyst performance, are successfully employed to deliver key intermediates and DS products with the highest possible activity and selectivity. Depending on the metal price, the synthetic complexity of the catalyst and its turnover frequency, the catalyst can be a critical cost factor in the entire DS process. Striving for the highest catalyst activity, favoring lower priced noble metals and ligands, nonnoble metals have a critical role to play in R\&D. In many cases, such work has resulted in the identification of greatly improved catalyst systems that enabled more sustainable and cost-efficient DS syntheses. Despite this success, homogenous catalysts have a number of drawbacks. The most notable is the contamination of the catalytic step and possible follow-up products with trace amounts of residual metal, thus resulting in a (high) number of tedious purification steps to deplete metal contamination in intermediates and even in DS materials. Furthermore, although catalytic processes are generally considered to be 'green', the syn- thesis of a catalyst and the catalytic process per se rarely reach an atom economy of even close to $100 \%$. Suzuki-Miyaura cross couplings, - in contrast to hydrogenation, for example - generate stoichiometric amounts of organic boron and halogen waste but still contribute to the overall low PMI, especially when compared to non-catalytic processes. ${ }^{[1]}$

The aim of Roche and the Paul Scherrer Institute collaboration on metal-organic frameworks (MOFs), highly crystalline and porous materials based on molecular building blocks, is to implement these catalytic materials in Suzuki-Miyaura cross coupling reactions to better understand their a) real-life performance, b) substrate tolerance, c) robustness, and d) ease of separation from the process-step product and ultimately to determine whether the MOFs result in more sustainable and cost-efficient processes than state-of-the-art, well-defined homogeneous palladium catalysts. Herein we will discuss aspects to be considered when employing a catalyst - whether homogeneous or heterogeneous - for a given transformation on an industrial scale.

\section{Homogeneous Suzuki-Miyaura Cross Coupling for the Synthesis of DS Intermediates}

Catalytic cross coupling reactions are an essential tool to build complex organic molecules. In particular, in Suzuki-Miyaura cross coupling reactions, highly active and chemoselective catalysts are applied to efficiently form $\mathrm{C}-\mathrm{C}$ bonds from halogenated aryls and boronic acid derivatives with a palladium catalyst (Fig. 1a). ${ }^{[2]} \mathrm{A}$ wide spectrum of catalysts and reaction conditions were employed. The reaction proceeds without ligands with a Pd(II) or $\mathrm{Pd}(0)$ source in polar aprotic solvents, such as dimethylformamide (DMF) or N-methypyrrolidone (NMP), at a high temperature above $100{ }^{\circ} \mathrm{C}$ using reactive aryl iodides and bromides. ${ }^{[3]}$ Under such conditions, palladium black forms and acts as a reservoir of soluble catalytic species, whose leaching is promoted by high reaction temperatures. This strategy, with so-called 'homeopathic' palladium catalysis, can afford Suzuki-Miyaura cross couplings at an extremely high substrate-to-catalyst ratio (S/C) above 20'000 under microwave irradiation; however, it is not applicable to DS intermediates of complex structures. Homogeneous palladium complexes, stabilized by electron-rich and bulky phosphines, such as $\mathrm{P} \mathrm{Bu}_{3}{ }^{[4]}$ and biphenyl-based ligands, ${ }^{[5]}$ form highly reactive catalysts for cross coupling reactions. The high reactivity is attributed to the formation of monoligated phosphine complexes. ${ }^{[6]}$ Such catalysts promote the reaction of aryl chlorides and result in high conversion and selectivity with broad tolerance of functional groups at temperatures below $100{ }^{\circ} \mathrm{C}$ and with $\mathrm{S} / \mathrm{C}$ higher than $200^{\prime} 000 .^{[5]}$ Ligands containing other coordinating moieties such as amines, ${ }^{[7]}$ imines, ${ }^{[8]}$ and $\mathrm{N}$-heterocyclic carbenes $(\mathrm{NHCs})^{[9]}$ are also effective. ${ }^{[10]}$ Examples of applied Suzuki-Myiaura cross coupling processes are shown in Fig. 1b. ${ }^{[11]}$

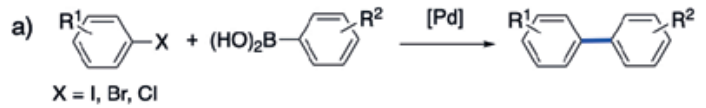

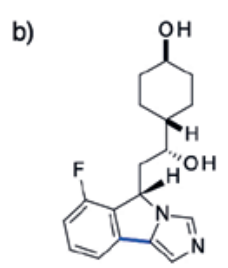

Navoximod

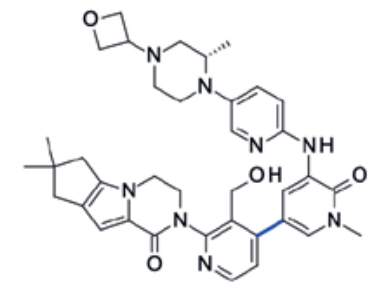

Fenebrutinib
Fig. 1. a) General scheme for a catalytic Suzuki-Miyaura cross coupling reaction. b) Examples of DS made by Suzuki-Miyaura cross couplings: Navoximod ${ }^{[11 e]}$ and Fenebrutinib. ${ }^{[11,9,}$ The bond formed by the SuzukiMiyaura reaction is highlighted in blue. 


\subsection{General Considerations in Process Development of Suzuki-Miyaura Cross Coupling}

From the perspective of process development, the separation and recycling of the metal in homogeneous Suzuki-Miyaura cross coupling reactions is straightforward in systems without ligands. Adding a ligand can make it more challenging to separate the catalyst from the product(s). Although some techniques, such as charcoal treatment and filtration over typical metal scavengers, are well established methods for the removal of residual transition metal impurities, a simple filtration to remove a heterogenized catalyst from the product(s) would speed up the process. Streamlining the work-up and reducing the number of unit operations (e.g. by avoiding charcoal filtration and extraction) will shorten production time, decrease waste, and reduce costs. The introduction of Suzuki-Miyaura cross coupling catalysts in the pharmaceutical industry should meet the requirements described below.

High catalytic performance and functional group tolerance. The catalyst should demonstrate constant high activity to allow for high turnover frequencies and reproducible high (chemo)selectivity to avoid side products, thus simplifying process development and maintaining low costs. However, even though some Suzuki-Miyaura cross couplings are reported to work at remarkably low $\mathrm{S} / \mathrm{C}<1000$, higher catalyst loadings can be tolerated when working with challenging substrates, low-volume products, and when alternative routes are unavailable or unsuitable. High catalyst loadings often result in complicated metal-removal operations and increased waste. A high functional group tolerance to allow for a wide variety of applications is critical, especially when employed in Discovery Chemistry programs where 'one catalyst fits all'. For pharma process applications, the functional group tolerance can be restricted to the present groups only, so catalysts with a narrower scope can find their use there.

Unlimited catalyst accessibility, low catalyst costs, and established supply chain. In an ideal world, the catalyst would be (a) commercially available from different vendors, (b) synthesized based on a straightforward manufacturing process, (c) available at low cost, in a suitable quantity and quality to meet the marketing demands and (d) free from IP protection. It is seldom that all of these requirements are met. Catalysts considered to be ideal may in the end be too costly or too time-consuming to produce. Sometimes third parties protect IP or there may be no available supply chain on time to meet demands. The pharma industry relies on trustworthy partners, such as a contract manufacturing organization (CMO) or a vendor who can ensure a constant supply of catalysts. Whereas typical heterogeneous catalysts are generally readily available from expert catalyst suppliers, specialty catalysts may not have a reliable supply chain. Establishing a supply chain of a newly introduced heterogeneous catalyst is often more complex than for a homogeneous catalyst due to the special techniques required for its preparation and characterization.

Consequently, the process for establishing a supply chain for a heterogeneous catalyst can take years and relies on a considerable financial investment. In particular in the pharmaceutical industry, the investment in a new catalyst comes with risks, including the possibility of failing to make a profit. The investment in a new catalyst is always based on a sound risk/benefit evaluation and is highly project-specific.

Straightforward procedure for cleaning the reactor, ease of implementation, and safety. From the moment a molecule is identified as a potential clinical candidate until the compound reaches the market, numerous obstacles must be overcome. A series of tox and clinical studies must be conducted, each requiring a different amount of the DS and in varying grades. Original syntheses in Discovery Chemistry may require optimization or modification. A catalyst can be replaced in a specific transformation once the commercial process is defined if there is a clear decrease of costs and improved impurity profile. The new catalyst would ideally work under the same or only slightly modified reaction conditions.

An important aspect is that each catalyst demonstrate stability in air, light, humidity, and residual amounts of water, which necessitates specific handling. Furthermore, multi-purpose equipment is used in the production of a DS, GMP standards must be met, and the cleaning of the corresponding equipment is highly regulated to avoid cross-contamination by impurities (e.g., residual trace metals, organic and inorganic impurities, and potentially genotoxic compounds). ${ }^{[12]}$ Metal leaching of the heterogeneous catalysts and reactor cleaning procedures need to be adequately addressed during process development to decide whether a new catalyst and process can be implemented or not. It is essential that all steps in the process are safe and that special measures are taken to ensure this.

\section{Heterogeneous Suzuki-Miyaura Cross Coupling Catalysts}

Bridging the gap between homogeneous and heterogeneous catalysis in Suzuki-Miyaura cross coupling has been a focus of catalysis research for more than 40 years. Heterogeneous palladium catalysts have been prepared in different ways, from simple metal nanoparticles supported on inorganic materials and polymers to molecular complexes immobilized on such materials. The efficiency of these catalysts has been discussed in comprehensive reviews. ${ }^{[13]}$ In the transformation of simple substrates, some catalysts have shown remarkable activity. Commercial Pd on inorganic supports such as $\mathrm{C}, \mathrm{SiO}_{2}$ and $\mathrm{Al}_{2} \mathrm{O}_{3}$ have been widely tested. $\mathrm{Pd} / \mathrm{C}$ was used to couple aryl halides with phenylboronic acid using $\mathrm{Na}_{2} \mathrm{CO}_{3}$ as a base at $120{ }^{\circ} \mathrm{C}$. The $\mathrm{S} / \mathrm{C}$ loading was as high as $20^{\prime} 000$ for aryl bromides and 2'000 for aryl chlorides. ${ }^{[14]}$ The authors of these studies later reported the use of palladium supported on metal oxides $\left(\mathrm{Al}_{2} \mathrm{O}_{3}, \mathrm{Ti}_{2} \mathrm{O}, \mathrm{CeO}_{2}\right)$ and zeolites $(\mathrm{Pd} / \mathrm{NaY})$ under similar conditions and at S/C of 20'000.[15] Palladium on carbon could be used on a multi-kilogram scale for the production of the simple DS intermediate 2'-methyl-4'-(2-oxo-1-pyrrolidinyl) biphenyl-4-carboxylic acid using a high Pd loading with S/C of 83.[16] Suzuki-Miyaura cross couplings were catalyzed by palladium nanoparticles immobilized on porous silica materials at $50{ }^{\circ} \mathrm{C}^{[17]}$ and on polymers at $60{ }^{\circ} \mathrm{C} . .^{[18]}$

Palladium complexes immobilized on polymers or inorganic supports, usually silica, have been explored to heterogenize molecular systems. MCM-41 was functionalized with Schiff base chelating sites to coordinate palladium and catalyze the coupling of aryl bromides with phenylboronic acid at $100{ }^{\circ} \mathrm{C}$ with $\mathrm{KF}$ as a base, with S/C > 20'000. ${ }^{[19]}$ An NHC main-chain organometallic polymer was used to catalyze the coupling of 4-chlorobenzaldehyde and phenylboronic acid at $80{ }^{\circ} \mathrm{C}$ with $\mathrm{K}_{2} \mathrm{CO}_{3}$ as a base with S/C of 2'000. [20] In most of these studies, the reactions were performed in polar solvent systems (water, short-chain alcohols, DMF, DME) with strong inorganic bases $\left(\mathrm{Na}_{2} \mathrm{CO}_{3}, \mathrm{~K}_{2} \mathrm{CO}_{3}\right.$, $\left.\mathrm{K}_{3} \mathrm{PO}_{4}, \mathrm{KOH}\right)$ and at high temperature $\left(80-130{ }^{\circ} \mathrm{C}\right) .{ }^{[21]}$ The scope is usually limited to the synthesis of small biphenyl molecules with limited functionalization.

The catalytic cycle of Suzuki-Miyaura cross couplings at high temperature occurs mainly in solution with dissolved palladium, making immobilization under such conditions unnecessary since the heterogeneous catalysts act as reservoirs for the metal.[21,22] Most existing immobilized palladium catalysts usually work at temperatures above $100{ }^{\circ} \mathrm{C}$. In addition, immobilized palladium catalysts based on inorganic materials are limited in substrate scope and cleaning of the equipment to meet GMP standards is time-consuming. These restrictions limit the interest of industry in the immobilization of molecular catalysts in cross coupling reactions. After decades of research, there is general skepticism about heterogenized homogeneous catalysts, with Hübner and co- 
workers joining Janssen Pharmaceutica in claiming that heterogenization will never be implemented in the industry. ${ }^{[22]}$ Lack of reproducibility, loss of performance, diffusion limitations, and increasing development time and high costs are among the reasons given. A major issue is that immobilized homogeneous catalysts on inorganic or polymeric supports such as carbon, silica, alumina, and Merrifield's resin add to the complexity of the system while losing molecular control and usually, performance, which is typical of molecular catalysts. It is less timeconsuming for the fine-chemical industry to use high throughput experimentation until target performance is reached. The novel research directions that MOFs open up may overcome such limitations, as described below.

\subsection{Metal-Organic Framework Catalysts in Suzuki- Miyaura Cross Coupling Reactions}

Over the past 20 years, MOFs have emerged as great candidates for catalytic research. ${ }^{[23]}$ MOFs are built by organic linkers connected by inorganic units to yield well-defined frameworks with a record high surface area. ${ }^{[24]}$ Many researchers have identified chemical versatility and structural control as key features in the development of tailored catalysts. Fig. 2 shows examples of the MOF structures UiO-66, ${ }^{[25]}$ MIL-101,[26] and HKUST-1. ${ }^{[27]}$ These structures can be modified by tuning the ligand and inorganic unit. MOFs are heterogeneous catalysts composed essentially of molecules. The molecular nature of MOFs and their large pores can overcome some of the limitations of standard immobilized catalysts, such as the lack of structural control at the molecular level and diffusion limitations. Thousands of publications and many reviews show their potential in organic chemistry. ${ }^{[23 \mathrm{acdfg}]}$ In addition, MOFs have features that neither homogeneous nor heterogeneous catalysts have.

The use of MOFs for catalysis of Suzuki-Miyaura cross couplings has been widely studied.[28] The catalytically active sites are atoms in the nodes of the material, nanoparticles supported on the framework and complexes with ligand sites at the organic linkers. A palladium MOF assembled with $\mathrm{Pd}(\mathrm{II})$ nodes and 2-hydroxypyrimidinolate linkers catalyzed the coupling of 4-bromoanisole with phenylboronic acid at $150{ }^{\circ} \mathrm{C}$ and with $\mathrm{K}_{2} \mathrm{CO}_{3}$ as a base, at S/C of 40.[29] Palladium NPs embedded in MIL-101 $(\mathrm{Cr})$ catalyzed the coupling of aryl chlorides with phenylboronic acid in water at $80{ }^{\circ} \mathrm{C}$ and with $\mathrm{NaOMe}$ as a base at $\mathrm{S} / \mathrm{C}=100 . \mathrm{Pd} / \mathrm{ZIF}-8$ and $\mathrm{Pd} / \mathrm{C}$ performed poorly under these conditions. ${ }^{[30]}$ Similar strategies were used for the synthesis of $\mathrm{Pd} / \mathrm{MIL}-53(\mathrm{Al})-\mathrm{NH}_{2}{ }^{[31]}$ and $\mathrm{Pd} / \mathrm{MIL}-101(\mathrm{Cr})-\mathrm{NH}_{2} \cdot{ }^{[32]}$ These materials were active in coupling aryl bromides at temperatures below $40{ }^{\circ} \mathrm{C}$ and aryl chlorides at $80{ }^{\circ} \mathrm{C}$, with milder carbonate bases and S/C of 200 and 30, respectively. Coordinating moieties in the organic linker, such as NHC, ${ }^{[33]} 2$-pyridyl-imine, ${ }^{[34]}$ and 2,2'-bipyridine ${ }^{[35]}$ were used to form defined complexes active in catalysis.

The benefits of MOF catalysts for Suzuki-Miyaura cross couplings have been widely demonstrated (proof-of-concept). The scientific and industrial communities must now bridge the gap between basic research and industrial application. High manufacturing costs of potential complex drug substances is an important aspect. If the manufacturing process can be shortened by reducing plant occupation, production costs can be significantly reduced. More efficient chemical processes are economically and ecologically beneficial.

MOF catalysts, modeled from homogeneous molecular catalysts, have all the necessary characteristics to be considered for an industrial Suzuki-Miyaura cross coupling pharmaceutical chemical process. Many publications report that heterogenizing a known homogeneous catalyst by a MOF can be a successful strategy for achieving a comparable or even superior performance in the catalysis of organic reactions (see above). In contrast to inorganic materials, MOFs consist of organic components and metals that can be easily removed from the reaction mixture in acidic, basic, or oxidizing treatments to ensure GMP compliance. From a reactor cleaning point of view, the pharma industry can consider MOFs more similar to the widely employed Raney nickel and Pd-Pt/C than silica-based catalysts. Manufacturers of MOFs, such as novoMOF AG (a PSI spin-off) a)

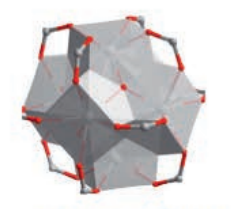

$\left[\mathrm{Zr}_{6}(\mathrm{OH})_{4} \mathrm{O}_{4}\right]^{12+}$

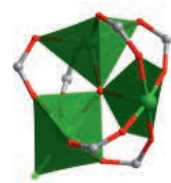

$\left[\mathrm{M}_{3} \mathrm{X}(\mathrm{O})\right]^{6+}$

$\mathrm{M}=\mathrm{Cr}^{3+}, \mathrm{Fe}^{3+}, \mathrm{Al}^{3+}$

$\mathrm{X}=\mathrm{F}, \mathrm{Cl}, \mathrm{OH}-$

c)

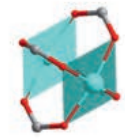

$\left[\mathrm{Cu}_{2}\right]^{4+}$
$+$

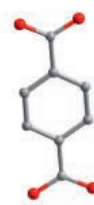

bdc
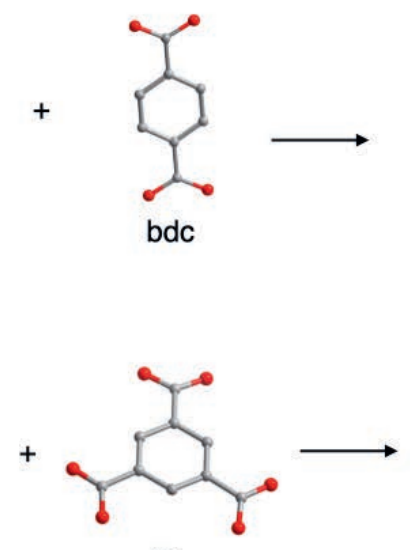

btc
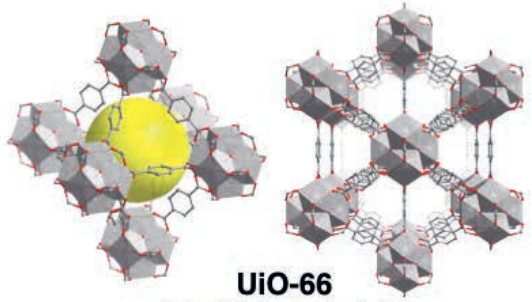

$\left[\mathrm{Zr}_{6}(\mathrm{OH})_{4} \mathrm{O}_{4}(\mathrm{bdc})_{6}\right]$
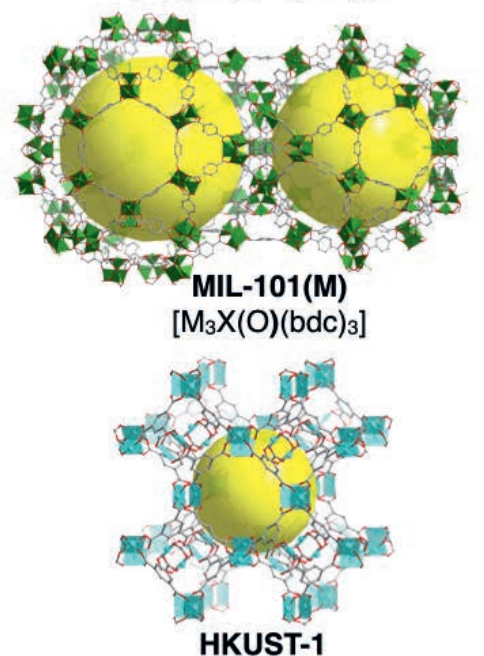

HKUST-1

$\left[\mathrm{Cu}_{3}(\mathrm{btc})_{2}\right]$
Fig. 2. Structure of the MOFs $\left[\mathrm{Zr}_{6}(\mathrm{OH})_{4} \mathrm{O}_{4}(\mathrm{bdc})_{6}\right](\mathrm{UiO}-66)(\mathrm{a})$, $\left[\mathrm{M}_{3} \mathrm{X}(\mathrm{O})(\mathrm{bdc})_{3}\right] \mathrm{MIL}-101(\mathrm{M})(\mathrm{b})$ and $\left[\mathrm{Cu}_{3}(\mathrm{btc})_{2}\right](\mathrm{HKUST}-1)(\mathrm{c}) . \mathrm{bdc}=$ 1,4-benzenedicarboxylate, btc $=$ 1,3,5-benzenetricarboxylate. 
and the Green Science Alliance Co., Ltd exist worldwide, thus helping to close the gap in the supply chain of catalytic materials. MOFs have extraordinary catalytic properties described below, thus giving them advantages over some of their homogeneous and heterogeneous counterparts.

Some MOFs show unique reactivity and selectivity, which is impossible or at least difficult to achieve with existing catalysts. Surface and pore effects may induce changes in selectivity and a chemistry that may modify the catalyst's speciation and favors the reactivity of specific substrates over others or enables chemical reactions that can happen only within the pores of a MOF. A chiral binaphthyl copper MOF with a phosphoric acid functionality catalyzed the Friedel-Crafts reaction between indole and imines. The homogeneous catalyst produced the $S$ enantiomer with $72 \%$ ee, whereas the corresponding MOF gave the $R$ enantiomer with $42 \%$ ee. ${ }^{[36]}$ The reversal of the selectivity originates from the restricted space available in the chiral environment of the MOF cavity. The cavity of MOFs can also induce changes in regioselectivity by preventing multinuclear mechanisms due to the isolated metal sites within the material.[37] The PSI group discovered that MOFs can transform the reactivity of an adsorbed catalytic intermediate from a nucleophile into an electrophile due to the confinement of the active centers within its pores. ${ }^{[38]}$ An increase in performance in asymmetric hydrogenation was observed while the molecular metal complex was absorbed within the pores of MOFs. ${ }^{[39]} \mathrm{A}$ recent study by the group at PSI has shown that the Co-catalyzed hydroformylation of olefins without directing groups can reach an unprecedented $90 \%$ branched selectivity by MOFs due to adsorption of the substrate, which acts on the kinetics of the reaction. [40]

The work-up of the process is simplified. A MOF catalyst can adsorb significant amounts of metal, ligand, and byproducts, facilitating the separation of the product, while minimizing chemical contamination, which may compromise the efficacy of the DS or may be dangerous for human health. The importance of the work-up is highlighted in the excellent review by Magano and Dunetz on the large-scale synthesis of pharmaceuticals with transition metal catalysis. ${ }^{[11 c]}$ The reaction crudes often contain thousands of ppm of metal residues and other genotoxic impurities, which may require several purification steps translating in more units of operation. Using a MOF catalyst may prevent or minimize contamination, thus limiting the necessity of additional work-up procedures. For example, palladium NP in MIL$101(\mathrm{Cr})-\mathrm{NH}_{2}{ }^{[41]}$ leads to reaction crudes with only tens of ppm of palladium.

MOF catalysts can operate in a fixed-bed flow reactor. Plugflow reactors, which may enable higher mass/heat transfer, are often used in the pharma industry, which would enable the straightforward implementation of MOFs. Preliminary reports on the use of MOFs as catalysts in flow reactors demonstrate their viability in the hydrolysis of nerve agent stimulants catalyzed by MOF$808,{ }^{[42]}$ in the addition to carbon dioxide to propylene oxide catalyzed by MIL-100(Sc) ${ }^{[43]}$ and in Suzuki-Miyaura cross couplings catalyzed by PdNPs/MIL-101(Cr)-NH ${ }^{\cdot}{ }^{[41]}$

MOF catalysts may be more stable than the corresponding homogeneous catalyst. If the MOF catalyst enables a higher turnover number (TON) than the homogeneous catalyst, more substrate molecules can be converted with less catalyst making the process more efficient. The MOF may stabilize catalytic species that are unstable in solution, leading to the recycling of the catalyst and lower catalyst loading. Sawano et al. demonstrated this effect and showed that a phosphine MOF can stabilize mono coordinated complexes that cannot be obtained in solution, ${ }^{[44]}$ thus enhancing the stability of the catalytic system in consecutive reaction runs with a pronounced loss of activity. Catalyst stability, especially in molecular catalysts for Suzuki-Miyaura cross coupling, is often affected by intrinsic decomposition pathways; ${ }^{[22]}$ heterogenization may not eliminate instability.

\section{Collaboration between PSI and F. Hoffmann- La Roche Ltd}

The initial tests with MOFs for Suzuki-Miyaura cross coupling reactions showed that the stability of the framework would have to be improved. Suzuki-Miyaura cross coupling reactions are generally performed in the presence of strong bases (e.g. $\mathrm{MOtBu}$ and $\mathrm{M}_{2} \mathrm{CO}_{3}(\mathrm{M}=\mathrm{Li}, \mathrm{Na}, \mathrm{K}, \mathrm{Cs})$, which are known to decompose the structure of many MOFs. Only the most stable MOF structures, such as MIL-101 and UiO-66, can be used. A systematic investigation of the stability of the well-known zirconium MOF UiO-66 revealed the effect of solvents such as water, dichloromethane, and THF on the crystallinity and porosity of the material upon treatment with acids and bases. [45] Although only the weakest bases could prevent decomposition of one of the most stable MOFs, this was an advantage in studying Suzuki-Miyaura cross coupling catalyzed by MOFs. Liquid bases are superior because they do not undergo solid/ solid interactions with the heterogeneous catalyst and have lower reproducibility issues, in contrast to $\mathrm{K}_{2} \mathrm{CO}_{3}$ and $\mathrm{K}_{3} \mathrm{PO}_{4}$. The particle size of inorganic bases has a strong effect on homogeneous catalysts in organic solvents and is strictly dependent on suppliers and mesh size. The use of weak liquids and nonnucleophilic bases such as $\mathrm{Et}_{3} \mathrm{~N}$ enhances the potential scalability and reproducibility of the heterogeneous MOF-based catalysis process.

The phosphine MOF (P-MOF) LSK-15 with MIL-101 topology ${ }^{[46]}$ was tested as a solid ligand for the palladium-catalyzed coupling of bromoanisole with boronic acid, which enabled the determination of the $\mathrm{C}-\mathrm{C}$ coupling and hydrodehalogenation selectivities. ${ }^{[47]}$ The molecularly defined heterogeneous palladium catalyst based on the P-MOF performed Suzuki-Miyaura cross coupling reactions under exceptionally mild conditions, while displaying higher selectivity than that achieved with $\mathrm{Pd}\left(\mathrm{PPh}_{3}\right)_{4}$. Determination of the palladium speciation by $\mathrm{Pd}$ and P K-edge X-ray spectroscopy showed that molecularly defined palladium-phosphine sites catalyze the Suzuki-Miyaura cross coupling with very high selectivity and that palladium nanoparticles promote hydrodehalogenation. An excess of phosphine in the MOF maintained the P-Pd moiety, the active site correlated with high selectivity. Future research will focus on finding stable MOF catalysts that will enable a large number of substrates under mild conditions and effectively reduce the waste produced by the reaction, thus decreasing the operation units in an industrial setting.

\section{Conclusion}

The heterogenization of homogeneous catalysts may become a powerful strategy for the industrial production of drug substances. MOFs provide the complementary platform to heterogenize highly active molecular catalysts and effectively decrease the PMI of a process. Table 1 shows key parameters relevant to an industrial Suzuki-Miyaura cross coupling catalytic process and qualitatively compares homogeneous, silica- and MOF-based heterogeneous catalysts. Present manufacturers ensure that MOFs combine the chemical flexibility of homogeneous catalysts with commercial availability. Even though their cost is high, if the simplified work-up allows for fewer purification units, an economic advantage may be achieved while 'greenifying' the process. The active sites of MOFs can be modeled from molecular catalysts meaning that reaction rates and chemoselectivity are closer to those obtained by homogeneous catalysts rather than particle-based heterogeneous ones. GMP compliance of MOF catalysts can be easily adapted from existing catalysts already employed by the industry, making them a potential realistic tool for the industrial production of DS. 
Table 1. Comparison between homogeneous, MOFs and inorganic support-based Pd catalysts for Suzuki-Miyaura cross coupling

\begin{tabular}{|l|l|} 
Catalyst & Homogeneous \\
\hline $\begin{array}{l}\text { Chemical flexibility of the } \\
\text { catalyst }\end{array}$ & Very high \\
\hline Commercial Availability & $\begin{array}{l}\text { Available from vendors and cus- } \\
\text { tom synthesis companies }\end{array}$ \\
\hline Cost & $\begin{array}{l}\text { Relatively low for simple ligands, } \\
\text { while complex ligands may be } \\
\text { quite expensive }\end{array}$ \\
\hline Reaction rate & $\begin{array}{l}\text { Generally relatively high at high } \\
\text { temperatures }\end{array}$ \\
\hline
\end{tabular}

Chemoselectivity

Work-up complexity

GMP compliance

\section{Heterogenized Silica-based}

Low

Standard supports are available, whereas custom synthesis for heterogeneization is limited

Very high for surface-modified derivatives

Generally, lower rates than the homogeneous derivative; activity may be high at temperatures above $100{ }^{\circ} \mathrm{C}$, where most catalysts behave like homogeneous ligandless catalysts

Moderate

Relatively simple

GMP standards are difficult to apply due to reproducibility and potential cross-contamination issues

\section{Heterogenized MOFs}

High

Few MOFs are commercially available, and custom synthesis companies exist

Generally high since complex linkers may be expensive

Some catalysts show high rates comparable to the corresponding homogeneous catalysts.

Still unknown due to limited published information, but potentially high

Relatively simple

MOFs can be treated like $\mathrm{Pd} / \mathrm{C}$ or $\mathrm{Ni}$-Raney catalysts and therefore can be adapted for GMP standards
[1] a) P. T. Anastas, J. C. Warner, 'Green Chemistry: Theory and Practice', Oxford University Press, New York, 1998; b) ACS Green Chemistry Institute, https://www.acs.org/content/acs/en/greenchemistry/what-isgreen-chemistry/principles/12-principles-of-green-chemistry.html.

[2] N. Miyaura, K. Yamada, A. Suzuki, Tetrahedron Lett. 1979, 20, 3437, https://doi.org/10.1016/S0040-4039(01)95429-2.

[3] a) A. Alimardanov, L. Schmieder-van de Vondervoort, A. H. M. de Vries, J. G. de Vries, Adv. Synth. Catal. 2004, 346, 1812, https://doi.org/10.1002/adsc.200404210; b) R. K. Arvela, N. E. Leadbeater, M. S. Sangi, V. A. Williams, P. Granados, R. D. Singer, $J$. Org. Chem. 2005, 70, 161, https://doi,org/10.1021/jo048531j.

[4] A. F. Littke, G. C. Fu, Angew. Chem. Int. Ed. 1998, 37, 3387, https:// doi.org/10.1002/(SICI) 1521-3773(19981231)37:24<3387::AIDANIE3387>3.0.CO;2-P

[5] S. D. Walker, T. E. Barder, J. R. Martinelli, S. L. Buchwald, Angew. Chem. Int. Ed. 2004, 43, 1871, https://doi.org/10.1002/anie.200353615.

[6] U. Christmann, R. Vilar, Angew. Chem. Int. Ed. 2005, 44, 366, https://doi.org/10.1002/anie.200461189.

[7] B. Tao, D. W. Boykin, J. Org. Chem. 2004, 69, 4330, https://doi.org/10.1021/jo040147z.

[8] G. A. Grasa, A. C. Hillier, S. P. Nolan, Org. Lett. 2001, 3, 1077, https://doi.org/10.1021/o1015676t.

[9] E. A. B. Kantchev, C. J. O’Brien, M. G. Organ, Angew. Chem. Int. Ed 2007, 46, 2768, https://doi.org/10.1002/anie.200601663.

[10] C. Amatore, A. Jutand, M. A. M'Barki, Organometallics 1992, 11, 3009, https://doi.org/10.1021/om00045a012.

[11] a) A. O. King, N. Yasuda, in 'Organometallics in Process Chemistry', Springer Berlin Heidelberg, Berlin, Heidelberg, 2004, p. 205, https://doi.org/10.1007/b94551; b) J.-P. Corbet, G. Mignani, Chem. Rev. 2006, 106, 2651, https://doi.org/10.1021/cr0505268; c) J. Magano, J. R. Dunetz, Chem. Rev. 2011, 111, 2177, https://doi.org/10.1021/cr100346g; d) D. G. Brown, J. Boström, J. Med. Chem. 2016, 59, 4443, https://doi.org/10.1021/acs.jmedchem.5b01409; e) R. Angelaud, S. Bachmann, A. Beyeler, D. Carrera, R. Fischer, M. GuillemotPlass, H. Hou, H. Iding, A. K. Kraft, A. Manns, R. Meier, K. M. Niedermann, M. Olbrich, K. Piechowicz, P. Rege, T. P. Remarchuk, L. Sirois, F. St-Jean, J. Xu, WO2018/175954 A1, 2018; f) D. Beaudry, T. Cravillion, F. Gosselin, N.-K. Lim, S. Malhotra, Q. Tian, H. Zhang, A. Gmehling, A. Fettes, S. Bachmann, WO2018109050A1, 2017; g) H. Zhang, T. Cravillion, N.-K. Lim, Q. Tian, D. Beaudry, J. L. Defreese, A. Fettes, P. James, D. Linder, S. Malhotra, C. Han, R. Angelaud, F. Gosselin, Org. Proc. Res. Devel. 2018, 22, 978, https://doi.org/10.1021/acs.oprd.8b00134.
[12] a) A. J. DeAngelis, P. G. Gildner, R. Chow, T. J. Colacot, J. Org. Chem. 2015, 80, 6794, https://doi.org/10.1021/acs.joc.5b01005; b) P. Ruiz-Castillo, S. L. Buchwald, Chem. Rev. 2016, 116, 1, https://doi.org/10.1021/acs.chemrev.6b00512.

[13] a) F.-X. Felpin, T. Ayad, S. Mitra, Eur. J. Org. Chem. 2006, 2679 https://doi.org/10.1002/ejoc.200501004; b) Á. Molnár, Chem. Rev. 2011, 111, 2251, https://doi.org/10.1021/cr100355b; c) L. Yin, J. Liebscher, Chem. Rev. 2007, 107, 133, https://doi.org/10.1021/cr0505674; d) A. Del Zotto, D. Zuccaccia, Catal. Sci. Technol. 2017, 7, 3934, https://doi.org/10.1039/C7CY01201B.

[14] R. G. Heidenreich, K. Köhler, J. G. E. Krauter, J. Pietsch, Synlett 2002, 1118, https://doi.org/10.1055/s-2002-32589.

[15] K. Köhler, R. G. Heidenreich, S. S. Soomro, S. S. Pröckl, Adv. Synth. Catal. 2008, 350, 2930, https://doi.org/10.1002/adsc.200800575.

[16] D. S. Ennis, J. McManus, W. Wood-Kaczmar, J. Richardson, G. E. Smith, A. Carstairs, Org. Proc. Res. Devel. 1999, 3, 248 , https://doi.org/10.1021/op980079g.

[17] H. Yang, X. Han, Z. Ma, R. Wang, J. Liu, X. Ji, Green Chem. 2010, 12, 441, https://doi.org/10.1039/B919175E

[18] E. Alacid, C. Nájera, J. Organomet. Chem. 2009, 694, 1658, https://doi.org/10.1016/j.jorganchem.2009.01.016.

[19] K. Dhara, K. Sarkar, D. Srimani, S. K. Saha, P. Chattopadhyay, A. Bhaumik, Dalton Trans. 2010, 39, 6395, https://doi.org/10.1039/C003142A.

[20] B. Karimi, P. F. Akhavan, Chem. Cотmun. 2009, 3750, https://doi.org/10.1039/B902096A.

[21] J. Sherwood, J. H. Clark, I. J. S. Fairlamb, J. M. Slattery, Green Chem. 2019 , 21, 2164, https://doi.org/10.1039/c9gc00617f.

[22] S. Hübner, J. G. de Vries, V. Farina, Adv. Synth. Catal. 2016, 358, 3 , https://doi.org/10.1002/adsc.201500846.

[23] a) J. Lee, O. K. Farha, J. Roberts, K. A. Scheidt, S. T. Nguyen, J. T. Hupp, Chem. Soc. Rev. 2009, 38, 1450, https://doi.org/10.1039/ B807080F; b) D. Farrusseng, S. Aguado, C. Pinel, Angew. Chem. Int Ed. 2009, 48, 7502, https://doi.org/10.1002/anie.200806063; c) A Corma, H. García, F. X. Llabrés i Xamena, Chem. Rev. 2010, 110, 4606, https://doi.org/10.1021/cr9003924; d) M. Ranocchiari, J. A van Bokhoven, Phys. Chem. Chem. Phys. 2011, 13, 6388, https://doi.org/10.1039/C0CP02394A; e) S. M. J. Rogge, A. Bavykina, J. Hajek, H. Garcia, A. I. Olivos-Suarez, A. Sepúlveda-Escribano, A. Vimont, G. Clet, P. Bazin, F. Kapteijn, M. Daturi, E. V. Ramos-Fernandez, F. X Llabrés i Xamena, V. Van Speybroeck, J. Gascon, Chem. Soc. Rev. 2017, 46, 3134, https://doi.org/10.1039/C7CS00033B; f) M. C. Wasson, C. T Buru, Z. Chen, T. Islamoglu, O. K. Farha, Appl. Catal. A 2019, 586, 117214 https://doi.org/10.1016/j.apcata.2019.117214; g) V. Pascanu, G. González Miera, A. K. Inge, B. Martín-Matute, J. Am. Chem. Soc. 
2019, 141, 7223, https://doi.org/10.1021/jacs.9b00733; hS. Kumar, B. Mohan, Z. Tao, H. You, P. Ren, Catal. Sci. Technol. 2021, 11, 5734, https://doi.org/10.1039/D1CY00663K.

[24] a) H. Furukawa, K. E. Cordova, M. O’Keeffe, O. M. Yaghi, Science 2013, 341, https://doi.org/10.1126/science.1230444; b) W. Lu, Z. Wei, Z.-Y. Gu, T.-F. Liu, J. Park, J. Park, J. Tian, M. Zhang, Q. Zhang, T. Gentle III, M. Bosch, H.-C. Zhou, Chem. Soc. Rev. 2014, 43, 5561, https://doi.org/10.1039/C4CS00003J.

[25] J. H. Cavka, S. Jakobsen, U. Olsbye, N. Guillou, C. Lamberti, S. Bordiga, K. P. Lillerud, J. Am. Chem. Soc. 2008, 130, 13850, https://doi.org/10.1021/ja8057953.

[26] G. Ferey, C. Mellot-Draznieks, C. Serre, F. Millange, J. Dutour, S. Surblé, I. Margiolaki, Science 2005, 309, 2040, https://doi.org/10.1126/science.1116275.

[27] S. S. Chui, Science 1999, 283, 1148, https://doi.org/10.1126/science.283.5405.1148.

[28] A. Dhakshinamoorthy, A. M. Asiri, H. Garcia, Chem. Soc. Rev. 2015, 44, 1922, https://doi.org/10.1039/C4CS00254G.

[29] F. X. Llabrés i Xamena, A. Abad, A. Corma, H. Garcia, J. Catal. 2007, 250, 294, https://doi.org/10.1016/j.jcat.2007.06.004.

[30] B. Yuan, Y. Pan, Y. Li, B. Yin, H. Jiang, Angew. Chem. Int. Ed. 2010, 49, 4054, https://doi.org/10.1002/anie.201000576.

[31] Y. Huang, Z. Zheng, T. Liu, J. Lü, Z. Lin, H. Li, R. Cao, Catal. Commun. 2011, 14, 27, https://doi.org/10.1016/j.catcom.2011.07.004.

[32] V. Pascanu, Q. Yao, A. Bermejo Gómez, M. Gustafsson, Y. Yun, W. Wan, L. Samain, X. Zou, B. Martín-Matute, Chem. Eur. J. 2013, 19, 17483, https://doi.org/10.1002/chem.201302621.

[33] G.-Q. Kong, X. Xu, C. Zou, C.-D. Wu, Chem. Commun. 2011, 47, 11005 , https://doi.org/10.1039/C1CC14393J.

[34] D. Saha, R. Sen, T. Maity, S. Koner, Langmuir 2013, 29, 3140, https://doi.org/10.1021/la304147j.

[35] H. Fei, S. M. Cohen, Chem. Commun. 2014, 50, 4810, https://doi.org/10.1039/C4CC01607F.

[36] M. Zheng, Y. Liu, W. Lin, W. Lin, C. Wang, W. Lin, S. Liu, W. Lin, Chem. Sci. 2012, 3, 2623, https://doi.org/10.1039/c2sc20379k.

[37] J. M. Falkowski, S. Liu, C. Wang, W. Lin, Chem. Commun. 2012, 48, 6508, https://doi.org/10.1039/c2cc32232c.
[38] G. Bauer, D. Ongari, X. Xu, D. Tiana, B. Smit, M. Ranocchiari, J. Am. Chem. Soc. 2017, 139, 18166, https://doi.org/10.1021/jacs.7b10928.

[39] B. Vilhanova, M. Ranocchiari, J. A. van Bokhoven, Chemcatchem 2016, 8 , 308, https://doi.org/10.1002/cctc.201500907.

[40] G. Bauer, D. Ongari, D. Tiana, P. Gaumann, T. Rohrbach, G. Pareras, M. Tarik, B. Smit, M. Ranocchiari, Nat. Commun. 2020, 11, 1059 , https://doi.org/10.1038/s41467-020-14828-6.

[41] V. Pascanu, P. R. Hansen, A. Bermejo Gómez, C. Ayats, A. E. Platero-Prats, M. J. Johansson, M. À. Pericàs, B. Martín-Matute, ChemSusChem 2015, 8 , 123, https://doi.org/10.1002/cssc.201402858.

[42] S.-Y. Moon, Y. Liu, J. T. Hupp, O. K. Farha, Angew. Chem. Int. Ed. 2015, 54, 6795, https://doi.org/10.1002/anie.201502155.

[43] B. R. James, J. A. Boissonnault, A. G. Wong-Foy, A. J. Matzger, M. S. Sanford, RSC Adv. 2018, 8, 2132, https://doi.org/10.1039/C7RA13245J

[44] T. Sawano, Z. Lin, D. Boures, B. An, C. Wang, W. Lin, J. Am. Chem. Soc. 2016, 138, 9783, https://doi.org/10.1021/jacs.6b06239.

[45] D. Cartagenova, F. A. Peixoto Esteves, N. T. Fischer, J. A. van Bokhoven, M. Ranocchiari, Inorg. Chem. Front. 2021 , https://doi.org/10.1039/DIQ100226K.

[46] F. L. Morel, M. Ranocchiari, J. A. van Bokhoven, Ind. Eng. Chem. Res. 2014, 53, 9120, https://doi.org/10.1021/ie403549v.

[47] D. Cartagenova, S. Bachmann, K. Püntener, M. Scalone, M. A. Newton, T. Rohrbach, P. Zimmermann, J. A. van Bokhoven, M. Ranocchiari, submitted manuscript, 2021.

\section{License and Terms}

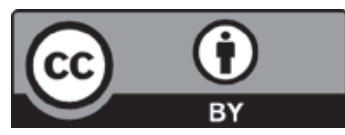

This is an Open Access article under the terms of the Creative Commons Attribution License CC BY 4.0. The material may not be used for commercial purposes.

The license is subject to the CHIMIA terms and conditions: (http:// chimia.ch/component/sppagebuilder/?view=page \&id=12).

The definitive version of this article is the electronic one that can be found at https://doi.org/10.2533/chimia.2021.972 